\title{
ALGUMAS REFLEXÕES SOBRE CIDADE SAUDÁVEL
}

José Luiz Riani Costa*

Resumo: É possivel ter uma cidade saudável? Esta pergunta é o ponto de partida para as reflexões desenvolvidas neste texto que foi a base da exposição feita pelo autor na Oficina de Trabalho sobre Cidade Saudáveis levada a cabo no V Congresso Brasileiro de Saúde Coletiva. A abordagem concentra-se na análise das relações que os homens mantêm "com os demais componentes da natureza", especialmente no espaço urbano, e das relações que os homens mantêm entre si, especialmente nas grandes cidades. Sendo a cidade uma expressão da sociedade que a produz e a consome, seria necessário "construir" uma sociedade saudável para que a cidade também fosse saudável. Finalmente, são analisados os dez requisitos para uma cidade saudável definidos pela Organização Mundial de Saúde - OMS.

Palavras - chave: Cidade Saudável, Urbanização, Sociedade - Natureza.

* Secretário Municipal de Saúde de Rio Claro/SP 
Toda vez que se fala em cidade saudável, surge o questionamento: É possivel ter uma cidade saudável? Este artigo, mais uma reflexão que pretende contribuir para a discussão, pretende identificar com o leitor aspectos históricos, culturais e políticos que interferem na questão.

Talvez, resgatando através da história o surgimento da cidade ea evolução da humanidade, seja possivel entender os comportamentos humanos que, provavelmente, ainda guardam bastante semelhança com os nossos ancestrais e não só com o que vivemos hoje. E a gente se esquece um pouco disso.

O geógrafo Claúdio de Mauro, hoje Prefeito Municipal de Rio Claro, que tem procurado tornar a cidade saudável, costuma definir a relação vida urbana e o meio ambiente da seguinte forma: "O ambiente é o espaço onde se dão as relações entre o homem e a natureza".

Hoje em dia, esta afirmação já está sendo repensada e redefinida entendendo o homem como um dos componentes da natureza e na sua relação como os demais: "O meio ambiente é o espaço onde se dão as relações do homem com os demais componentes da natureza".

A cidade moderna, a cidade contemporânea, entretanto tem esquecido o homem nesta relação. A pergunta que se faz ao se deparar com um problema é: qual a ligação do homem com os demais componentes da natureza?

Na verdade, o homem está sempre presente mas como um ator com uma enorme capacidade para, inclusive, corrigir a natureza (CARVALHO et al, 1994). Um exemplo, deste tipo de visão da relação homem natureza é a retinilização do rio Tietê. Na opinião do homem, racional, técnico, em quase todas as cidades há um rio "pouco inteligente" que não sabe caminhar, e vai tortuoso, com meandros, e aí, o homem que tudo sabe, corrige o rio fazendo com que ele tenha um caminho reto, mais lógico, mais racional, permitindo uma melhor utilização do espaço. E o rio, infelizmente, além de "pouco inteligente" é "teimoso", porque quando chove bastante ele volta para o lugar que ele utilizava antes.

O rio, na opinião do homem é cruel e vingativo, pois conforme dizem as manchetes " $\mathrm{O}$ rio invadiu as casas", ou "O rio invadiu a pista da marginal".

Na maioria das vezęs ocorre é exatamente o contrário: "A pista invadiu o rio", "As casas invadiram o rio", "A cidade invadiu o rio". E ele simplesmente está respondendo à agressão que o ser humano provocou à natureza. 
Assim, muitas intervenções -e as cidades têm permitido aos homens uma intervenção brutal sobre a natureza - têm sido feitas sem se conhecer muito ou sem se preocupar com as respostas de médio e longo prazo.

Outra coisa em relação aos nios na área urbana é a tendência de muitas cidades canalizarem todos os córregos, utilizando as margens para fazer as famosas avenidas de fundo de vale. "Quando você encontrar uma avenida tortuosa fora do tabuleiro de xadrez pode apostar que tem um rio embaixo" $A$ hipótese, é uma grande chance ter um rio canalizado. E em Rio Claro é assim. Certa vez, ao atravessar uma dessas avenidas eu parei com o carro entre as duas pistas, e falei para as crianças, "Nós estamos em cima do rio". E aí ficamos um pouco parados ali tentando reconstruir o que teria sido aquela paisagem natural. Imaginamos uma ponte de madeira, o rio passando com suas águas límpidas, cheio de peixes, as margens com árvores e pássaros e borboletas, as pessoas caminhando ao longe desse rio, respirando ar puro, curtindo a natureza. Enquanto imaginávamos esta paisagem, os carros passavam apressados nos dois sentidos da avenida e um dos meus filhos falou assim: "Mas e os carros, onde iriam?".

Então, ele introjetou a lógica de aproveitar os fundos de vale, para cortar a cidade. Eu falei: "Mas tem tantos outros espaços, por que que a gente teve que destruir o rio para fazer 0 traçado das ruas? Se a malha viária foi traçada a muitos anos, por que o rio foi opção para se eliminar? E casas que foram construídas não podem ser demolidas para abrir uma avenida de integração, uma avenida de trânsito rápido? Destruir o rio, transformar a natureza é mais barato?"

A nossa intervenção sobre a natureza na construção da cidade está chegando a um ponto de difícil retomo e quase sem solução. Isso nomalmente acontece com os resíduos da cidade; o rio está recebendo grande carga de esgoto, em volume muito maior que os afluentes naturais, e com isso ele acaba morrendo. E então, como o rio já está morto, você enterra, coloca uma laje de concreto em cima. As empresas de cimento e as empreiteiras vão agradecer muito. Aliás, essas empresas conseguiram incluir emendas no orçamento e nos últimos anos o Brasil todo fez canalização de córregos. E bota uma avenida para andar junto com o rio e o problema do trânsito está resolvido e não se pensa no transporte coletivo, não se pensa também na proximidade entre o local de moradia e trabalho, entre moradia e consumo. Só se pensa em facilitar o deslocamento rápido e não o uso do espaço urbano que prescinda dos grandes deslocamentos. Nessa perspectiva, é possível ter uma cidade saudável?

Também gostaria de refletir um pouco sobre como é a vida nas nossas cidades. Tem um documentário produzido pela TV Cultura, "Prisioneiros do medo", em que aparece a estratégia, 
a prática de construir condomínios fechados, as crianças indo com motorista e guarda-costas para a escola, os empresários indo com carro blindado para o seu trabalho, a familia ou os jovens frequentando shopping, fechado e com segurança em todas as portas, as pessoas não tendo mais contato com a cidade, com as demais pessoas. E o psicanalista Jurandir Freire Costa falava que nesta sociedade em que o homem não reconhece o outro como seu semelhante, éo estado da barbárie. Então os crimes que estão acontecendo por aí são causa e/ou consequência desse tipo de comportamento. Como falar em construir uma cidade saudável com o medo, com a violência, com a agressão que existe entre os componentes de uma mesma cidade?

Onúmero de horas que a gente fica fora de casa ou fora do convivio familiar, por exemplo, preso no trânsito numa grande cidade é outro grande obstáculo a uma cidade saudável. Quem estuda e discute muito a cidade, analisa que o espaço da cidade antiga tinha uma escala humana, e que a cidade atual perdeu a escala humana, pelo tamanho dos edifícios, pela extensão das vias públicas, pelo número de pessoas que você não consegue estabelecer contatos, conhecer (ENGELS, 1968; VELHO, 1973). Então a cidade perdeu a dimensão humana. Mas eu também estou preocupado em perder a dimensão humana, não só no espaço mas no tempo também. $A$ cidade do tudo rápido, do computador, da informação instantânea em qualquer parte do mundo. No programa esportivo, você vê gols de todos os campeonatos de todos os paises, e no noticiário você vê a guerra de todos os paises, ultrapassando a escala humana até para captar informaçőes e processá-las. "A cidade é a expressão da sociedade que a produz e que a consome" dizem também os estudiosos da cidade (ROLNIK, 1988; RODRIGUES, 1993). Então, se a cidade é a expressão da sociedade que a está produzindo, que a está consumindo, essa cidade só será saudável se a sociedade se organizar de forma diferente. Será que o nosso objetivo não seria transformar a sociedade, mudar a forma como se organiza a sociedade? E a sociedade ser saudável e, em consequência, a cidade ser saudável? E ai alguém pode falar. "Bom, mas isto é utópico, teríamos que mudar todas as bases do sistema produtivo, da escala de valores..." Talvez tenhamos que fazer isso mesmo, só que não dá para esperar que isso aconteça para se melhorar as condições de vida da cidade. Assim, o projeto cidade saudável pode vir para nos ajudar, sem ser a solução, apontar algumas possibilidades de reorganização da vida na cidade. Para finalizar, seria oportuno lembrar os dez requisitos para uma cidade saudável definidos pela Organização Mundial da Saúde-OMS com breves comentários. (OMS, 1995)

"Um ambiente fisico limpo e seguro". Para algumas cidades isso é muito dificil conseguir, especialmente as metrópoles. Para uma cidade média, uma cidade pequena, há uma possibilidade maior, desde que o desenvolvimento seja planejado, respeitando a relação do homem com os demais componentes da natureza. 
"Um ecossistema estável e sustentável". Este item nos remete à discussão da cidade sustentável, ou do desenvolvimento sustentável. Ao se falar em desenvolvimento sustentável, entendido como um processo de desenvolvimento que atenda as necessidades básicas desta e das futuras gerações, surge a pergunta: "Quem é que define as necessidades fundamentais?" "Que necessidades nós vamos definir?" Se definimos o padrão de consumo de alguns países do assim chamado "primeiro mundo" provavelmente não teremos matéria prima, energia e espaço para depositar os resíduos, tomando impossível um ecossistema sustentável.

"Alto suporte social, sem exploração". Não é necessário lembrar o quanto estamos longe deste ponto.

"Alto grau de participação social"; que vem sendo muito enfatizado em nosso país, especialmente no Sistema Único de Saúde.

"Necessidades básicas satisfeitas". Este item diferencia também um projeto de cidade saudável para um país subdesenvolvido e de um país desenvolvido. Aqui, para se falar em cidade saudável seria necessário garantir, a todos, os fatores determinantes e condicionantes da saúde definidos na legislação, como: alimentação, moradia, trabalho, renda, transporte, saneamento, etc.

"Acesso a experiências, recursos, contatos, interações e comunicações". Fica difícil garantir tudo isso se nas grandes cidades as pessoas não conversam, as pessoas não se reconhecem, como comentado anteriomente.

"Economia local diversificada e inovativa". Todos os problemas que as cidades "especializadas" em um só setor produtivo têm sofrido neste tempo da globalização.

"Orgulho e respeito pela herança biológica e cultural". É cada vez mais evidente a necessidade que temos de conhecer nossa origem e respeitar a história de nosso povo.

"Serviços de saúde acessíveis a todos".

"Alto nível de saúde".

Portanto, apenas nos dois últimos requisitos de uma cidade saudável apareceu algo mais diretamente ligado ao setor saúde. Mas muita gente quando fala em cidade saudável liga muito com serviços de saúde, ou com profissionais de saúde. Talvez essa idéia tenha sido reforçada porque a discussão tem sido conduzida pela Organização Mundial de Saúde, pela Organização Pan-Americana de Saúde, pela Secretaria de Saúde, pelo Ministério da Saúde. Na verdade, o 
grande volume de ações para um projeto de cidade saudável escapa ao sistema de saúde, especialmente aos serviços de saúde. O Projeto Cidade Saudável pressupõe, portanto, um novo projeto de cidade e uma sociedade renovada.

Essas eram algumas questões que a gente tinha pensado em trazer para o debate e eu aproveito para colocar à disposição dos interessados o texto "Saúde Meio Ambiente Urbano: processo de urbanização e seus reflexos na saúde" (RIANI COSTA, 1996) que se constitui no relatório parcialda pesquisa que desenvolvo na universidade.

\title{
REFERÊNCIAS BIBUOGRÁFICAS
}

CARVALHO,P.F. etal Questão ambiental demandando uma nova ordem mundial. In: SOUZA,M.A A. et al. Natureza e sociedade de hoje. 1994.

ENGELS, F. A situação da classe trabalhadora na Inglaterra. São Paulo, Global Editora, 1968. ORGANIZAÇÃO MUNDIALDA SAÚDE. Veinte pasos para formular un proyeto de ciudades sanas. Washington, 1995.

RIANI COSTA, J.L. Saúde e meio ambiente urbano: o processo de urbanização e seus reflexos na saúde. UNESP, 1996.

RODRIGUES, A M. Movimentos sociais. IFCH/UNICAMP, 1993.

ROLNIK, R. O que é cidade. São Paulo, Brasiliense, 1988.

VELHO, O.G., org. O fenômeno urbano. São Paulo, ZaharEd., 1973.

\begin{abstract}
Summary: Is it possible to have a healthy city? This question is the starting point for reflections present in this text that served as basis for the exposition by the author in the Healthy Cities Workshop at the $V$ Brazilian Congress of Collective Health. The approach focuses the analysis of the relations of man and "the other elements of nature" especially in the urban space and the human interrelations, especially in big cities. Having the city as an expression of society that produces and consumes it would be necessary to "build" a healthy society form the city to be healthy. Finally the ten requisites for a healthy city defined by WHO are analyzed.
\end{abstract}

Key words: healthy city; urbanization; society-nature 